Article

\title{
Handling Points of Interest (POIs) on a Mobile Web Map Service Linked to Indoor Geospatial Objects: A Case Study
}

\author{
Kwangseob Kim and Kiwon Lee *(D) \\ Department of Electronics and Information Engineering, Hansung University, Seoul 02876, Korea; \\ engintruder@hansung.ac.kr \\ * Correspondence: kilee@hansung.ac.kr; Tel.: +82-2-760-4254
}

Received: 4 April 2018; Accepted: 13 June 2018; Published: 14 June 2018

\begin{abstract}
Managing geo-based indoor content is important, because the components used to construct an urban environment are complex. Geospatial data are available worldwide, but services are tailored only to local features. As the accuracy of online maps increases, the buildings in a web-mapping service can be created exactly as they are, in terms of actual features and geometric properties, and can provide some information on indoor elements. Nevertheless, not many practical use cases exist, as the available scope and volume of indoor content are limited. In Korea's metropolitan areas, an indoor geospatial information management scheme was built to manage internal facility information for public and underground buildings on a three-dimensional (3D) basis and to provide online visualization services for users. Based on this enterprise system for public use of indoor 3D content, we conducted a case study with add-on features to manipulate and manage data by adding two-dimensional (2D) building data that are linked to the 3D models. We also changed the classification system of the points of interest (POIs) for each internal facility. To enhance public usability, a portion of the usable information in this scheme can be offered via an open application programming interface (Open API). To create a 2D POIs obtained from an indoor 3D object that was provided as a relative coordinate with only 3D geometric features, several steps were needed: adding the object to the system, storing the object as an absolute coordinate, and linking the object with an outdoor mapping service. In addition, to provide more useful information about indoor POIs generated from 3D models for users, detailed information should be further managed by directly using the Open APIs designed in this study. Subsequently, a mobile web mapping service system to visualize indoor contents was deployed to deliver practical processing and improvements based on the deployed Open API. The possibility of effective management and application of POIs related to indoor contents was confirmed through the mobile web-mapping demo service that was established using Open API.
\end{abstract}

Keywords: two-dimensional (2D) web map; three-dimensional (3D) object; mobile; point of interest (POI); open application programming interface (Open API)

\section{Introduction}

Most people in urban areas spend more time inside than outside. As building technologies develop and the area of indoor spaces grows, many facilities and services can be provided inside a building. However, most geospatial information services available to public users are outdoor mapping services that include navigation for locating buildings or specific areas, or directions to a certain place. Nevertheless, if the user has not previously visited the building or if an internal space is large and complex, difficulties are encountered in finding the facilities or services that users seek. In 
particular, information about the installation and inside space of a building is important if a disabled person uses the building or if an emergency occurs. The general services offered in most geospatial information fields are typically close to outdoor spaces. Studies on indoor spaces have been conducted on a variety of topics. In particular, since indoor location is technically more limited than outdoor space, various methods have been considered to solve the problem [1-3]. Research has also been performed to classify indoor space models for indoor emergency situations [4]. Open community projects such as Open Street Map (OSM) [5] have also been established. Regarding points of interest (POIs) in the geospatial application field, POI analysis or search has been studied, rather than POI generation and the design of its attributes [6-8].

As for the quality of POI, automatic data matching is necessary for schema matching given the heterogeneity of OSM and the representation of authoritative datasets [9]. The fitness of use of a POI relates to how its geographical information is represented [10]. Openness is key to the success of building information modeling (BIM) and the integration of a Geographic Information System (GIS) [11]. The information model for BIM enabled the creation and exchange of boundary representations of topological objects that could be merged into a three-dimensional (3D) legal space overview map [12]. Models and algorithms used in a tourism recommendation system based on POI profiles were analyzed [13]. Presently, Google provides extra indoor mapping services, and information has been provided for many buildings located in 15 countries, including the United States, Britain, and Japan. Although geometric information about the buildings and the placement of some important facilities is supplied, this information is limited [14]. Providing detailed indoor space information is difficult because of the large geographical range of the map data [15].

The Seoul Metropolitan Government has introduced and managed a system that provides the public with indoor geospatial information about public and underground constructions since 2015 [16]. Currently, the online service only is available in the Korean language. On this operational system, attempts have been made to develop value-added services using a database built for this service; this research can be considered a new attempt. A framework for a three-dimensional underground cadastral system was proposed to register the rights, responsibilities, and restrictions corresponding to the 3D underground properties using indoor mapping for as-built BIM [17]. The system developed at this time is the partial outcome of an ongoing phased project to model, upload, and manage the internal 3D models and facilities for public and basement buildings. This study added features to scale up the services to manage more detailed facility information. Generally, most government agencies consider, construct, and provide the necessary information for BIM. The data provided can be used in various ways, depending on the formats preferred by public users. The same is true of indoor geospatial information management systems administered by the metropolitan government. As the system is deployed, data models for buildings are continuously being created and uploaded for civilian use or business applications. However, providing data alone is insufficient to maximize the use of such data models. In addition to providing more detailed information about indoor geospatial contents, this study also designed the taxonomy required from the user's perspective to control the content. In particular, some of the additional data could be provided using an open application programming interface (Open API) that can then be processed into secondary services derived by users.

The purpose of this study was to suggest a conversion scheme of indoor 3D objects into 2D georeferenced POIs. In particular, Seoul City applied this method by separately deploying a POI database, because it did not consider the connection with the 2D web map service at the beginning when the database of indoor 3D geo-objects was built. The reason for implementing mobile services in this study was to endow field operators with the account permissions to immediately create modifications or edits. In the process of building the 2D POI database, it was suggested that field operators immediately apply the additional data models to conveniently enter attribute information.

Section 2 briefly reviews the current status of the web-based indoor information management system that is used in this case study and explains in detail the add-on functions that were designed and implemented. Section 3 describes the results of designing and applying an open data plan so 
that additional deployed data could be used for different services. Section 4 describes the results of implementing a mobile web-mapping service to identify the accessibility of open data.

\section{Web-Based Management System for Urban Facilities}

\subsection{Component Review of Indoor Content Service System}

In 2014, the Seoul Metropolitan Government established a service plan to search for and verify information about facilities. The government simultaneously designed and constructed a system to model and manage its public buildings and underground facilities. In 2015, data in the form of a web-based indoor map service for Seoul City was made available for general users. As of March 2018, 3D-based models had been created for 209 subway stations, 82 public structures, and 17 underground malls. However, not all buildings have been 3D modeled [18]. The functionality of these models extends to the creation of examples of buildings that are uploaded for management, visualization, and web publishing. Location information for the facilities inside 3D buildings is also supplied. Even so, only the location information for internal facilities has been provided; no detailed information about installations is available. From 2016 to 2017, the government created and uploaded 3D models to enhance the use of data while adding 2D-based data on internal facility details to the management organization. As public disclosure policy was actively pursued on a global scale, policies were also created to release indoor geospatial information data. As of 2018, the indoor information management organization established techniques to manage 2D models for public buildings and underground facilities and to provide detailed information on several internal facilities. In particular, existing management systems were further designed and deployed to add 2D data to the 3D modeled building base and to discern and disclose detailed information.

Features for POI information and 2D object management added on to the indoor 3D map service system are represented in the existing system configuration, as shown in Figure 1. Functions related to $2 \mathrm{D}$ include practical features like POI coordinate conversion function, Open API for open data usage, and POI attribute information obtained by an additional classification process. In addition, a geometric editing function was further configured to modify the reference point by moving or rotating the building location for the case where 2D objects on the surface do not match the actual coordinates.

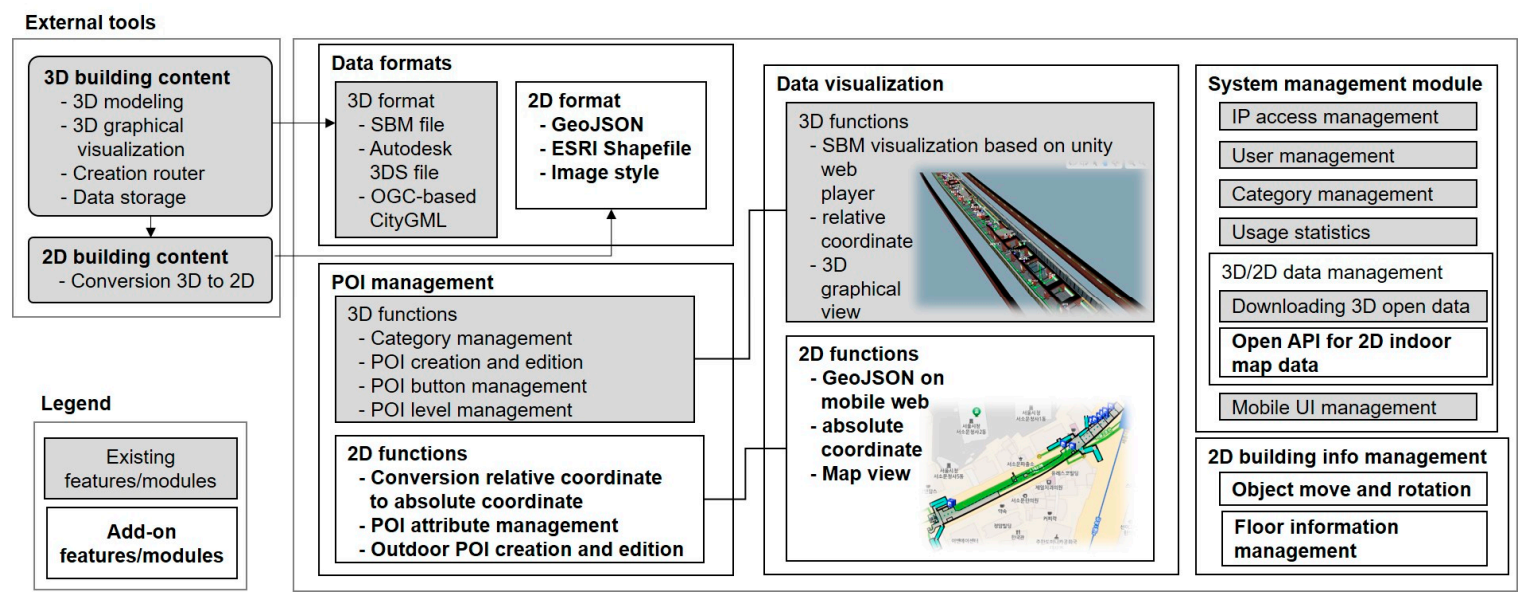

Figure 1. Main features of the indoor map service system. Add-on functions are shown as white boxes, and the gray shaded boxes represent existing functions for three-dimensional (3D) contents.

\subsection{Add-On Functions and Application Examples}

All 3D models of buildings in a web-based indoor map service for Seoul City are composed of their relative coordinates. The reference point and rotation angle, which are the absolute coordinate data that specify the real position of each building, are kept separate. Using these attributes, the relative 
coordinates of the 3D model are changed into absolute coordinates. Then the converted absolute coordinates are created using the Geo-JavaScript Object Notation (GeoJSON) format, which is the format used to encode a variety of geographic data structures for file exchange on the web. The indoor building objects include walls, spaces, stairs, windows, and doors, and each one has been created with one GeoJSON file. When the model coordinates of a building are converted, the coordinates of the positions of the POIs inside the facilities are converted from relative to absolute coordinates. These absolute coordinates can be mapped to a tiled background map. The POI classification system for the internal facilities of the 3D model is divided into facilities for disaster prevention, mobility, guidance, and restrooms. Additional design and construction of the 2D data management system have contributed to the expression of more general facility classifications to enhance the system's functionality. The additional taxonomy includes mobility facilities for the disabled, subway gates, building entrance doors and outlets, and shopping centers. As a final step, this system was made available to developers and general users on the Internet and mobile apps by deploying and releasing it separately under the Open API.

The added functionality can be divided into three parts, as shown in Figure 2. The first is for 2D data visualization and management processing, as shown in Figure 2a. The 3D data can be displayed by the $3 \mathrm{D}$ viewers that are included in the management system and added or erased from the indoor POI locations. However, no visualization or management features exist for these points, because the 2D data were not collected during the conception of the initial organization or the design stage of the public service. Although 3D data enable visualization of geometric information for the building, 2D data can be visualized using a background map that is composed of a tile structure. However, there are cases where the reference points of the 3D model, composed of relative coordinates, are not the same as the actual positions. This is why it is necessary to visualize such data on the management system web and to enable the manager to change the placement or angle at random to update the information. One of most important functions is internal facility detail management, as illustrated in Figure $2 b$. This is because internal facility detail management functions are used to visualize and follow the stored POI information that is based on the newly added taxonomy of mobility facilities for the disabled, including subway gates, building entrance doors and outlets, and shopping centers. This information also includes basic features such as distance and field measurements and object selection, which are provided as a basis in the visualization and management of the base map. The database in this online service system was designed and the user interface was configured to store detailed data. The types of detailed information include text and pictures.

Figures 3 and 4 show the application examples used to visualize and manage 2D data. The user interface consists of input and selection windows and a map-based data manipulation panel. Figure 3a shows how 2D data can be visualized in different ways by selecting multiple indices and objects as a screen. The types of objects inside the building include walls, columns, windows, elevators, doors, space, stairs, and escalators. Figure $3 \mathrm{~b}$ represents a feature that manages the attributes of indoor spaces. Of these objects, space indicates a room within a building. Since the indoor objects of a building have specific functions, attributes may be necessary. 
(a)

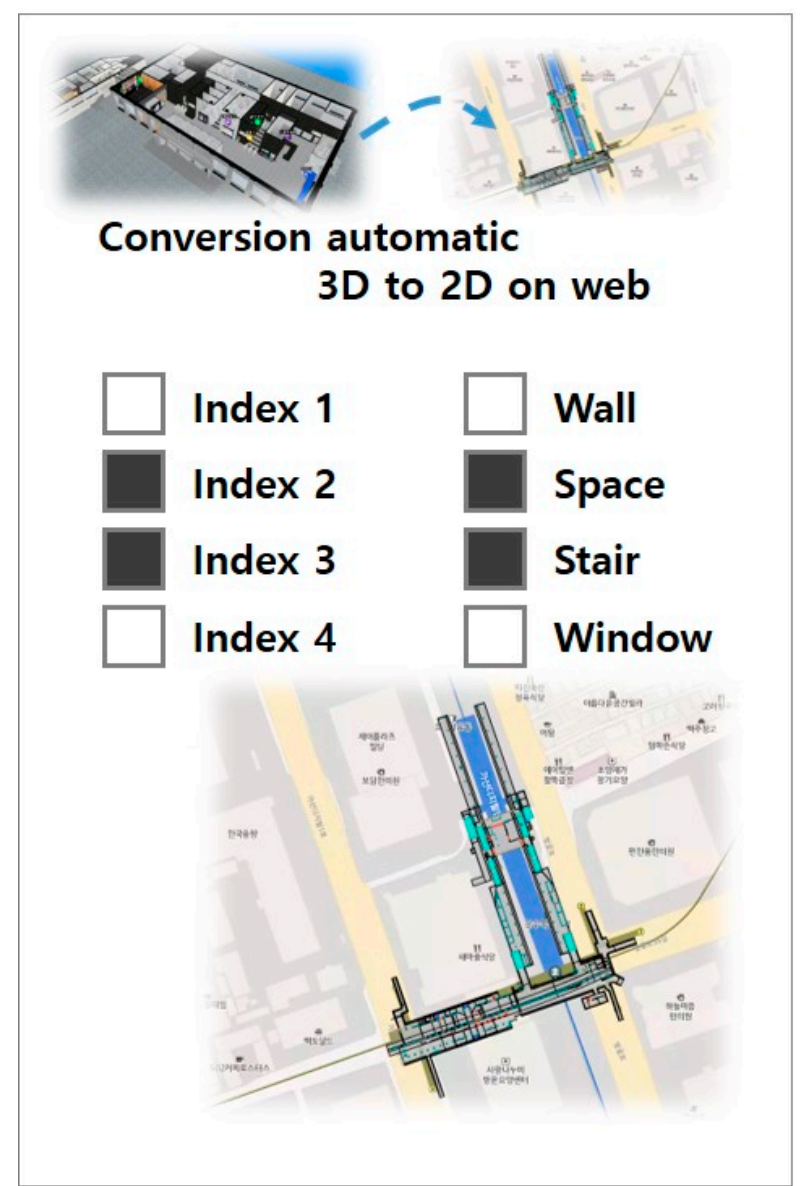

(b)

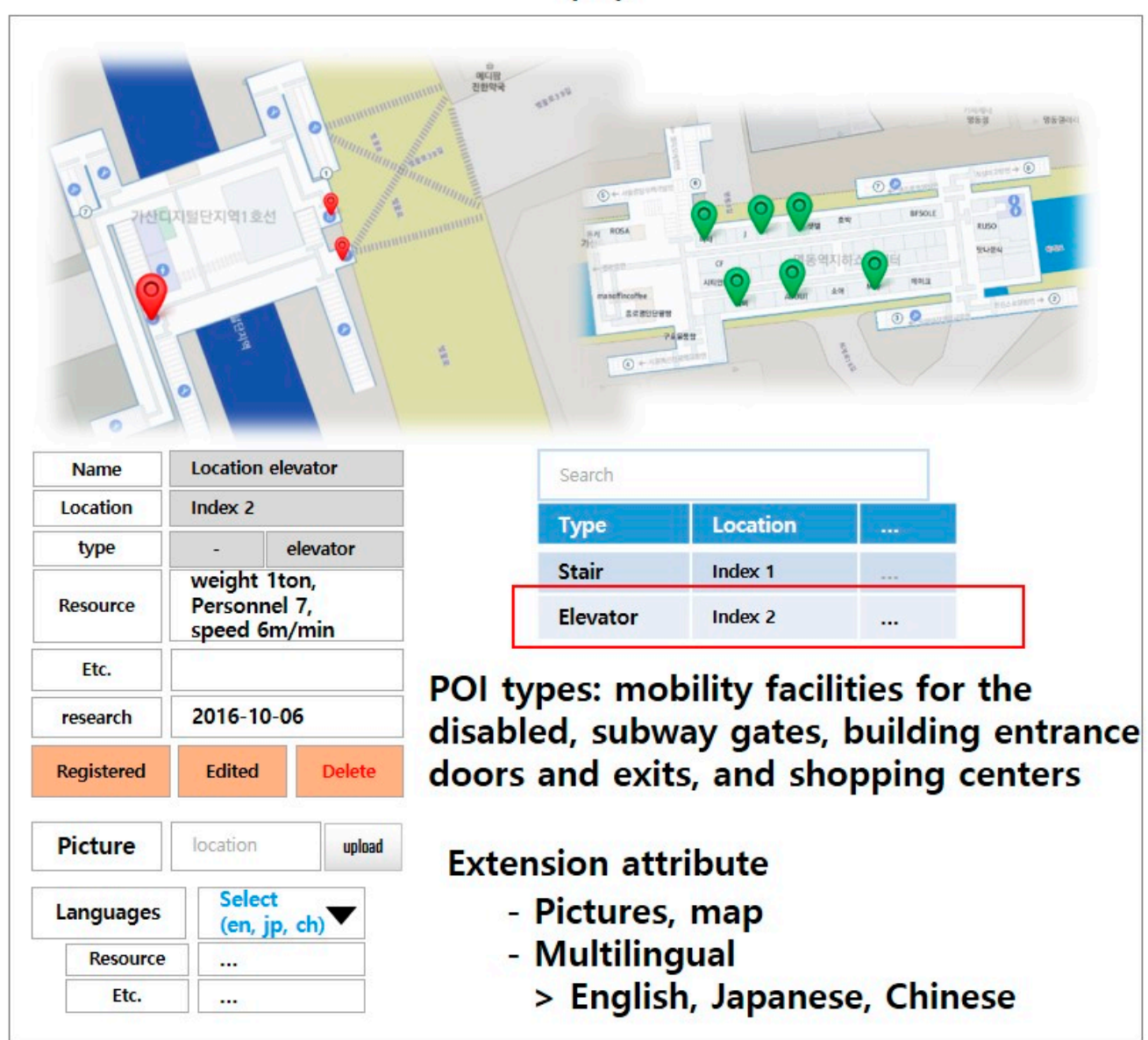

Figure 2. Two-dimensional (2D) data model for an indoor content management system: (a) geospatial object visualization and management, and (b) management mode of indoor points of interest (POIs) and open application programming interface (API). 
(a)

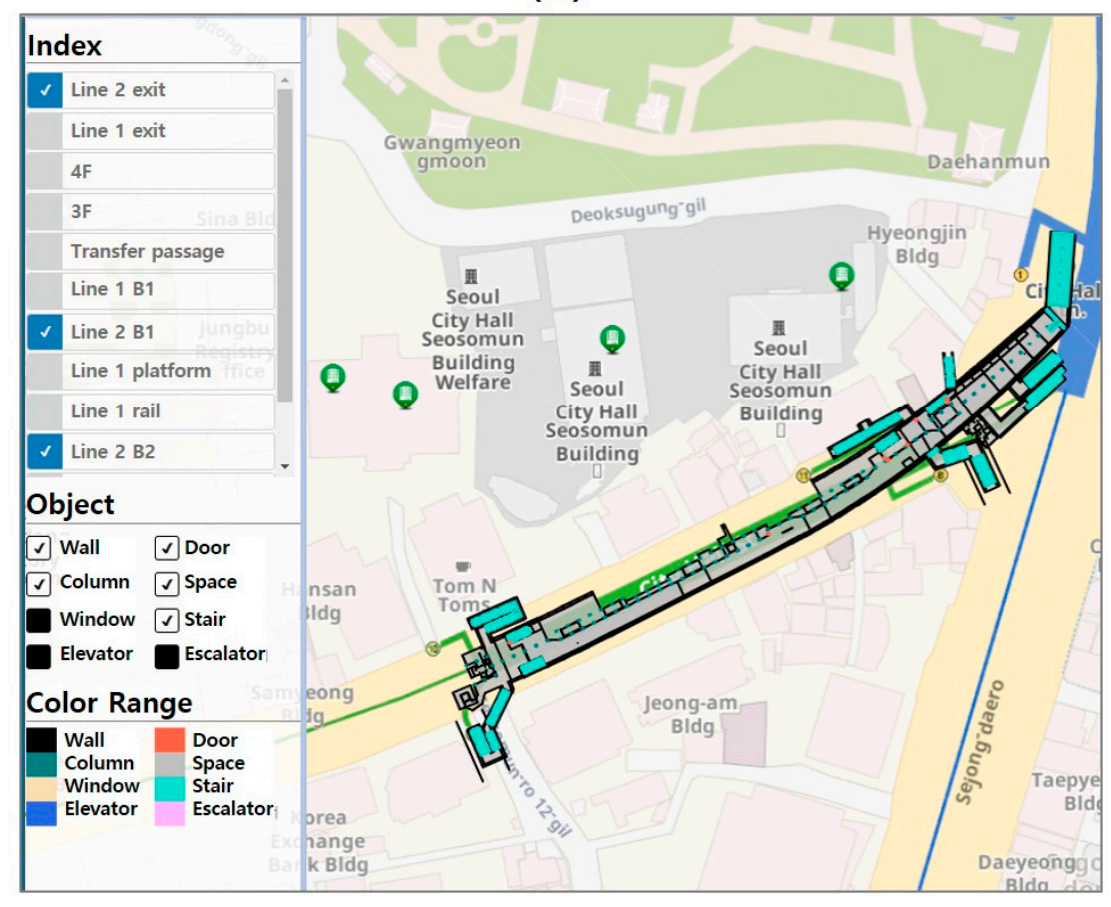

(b)

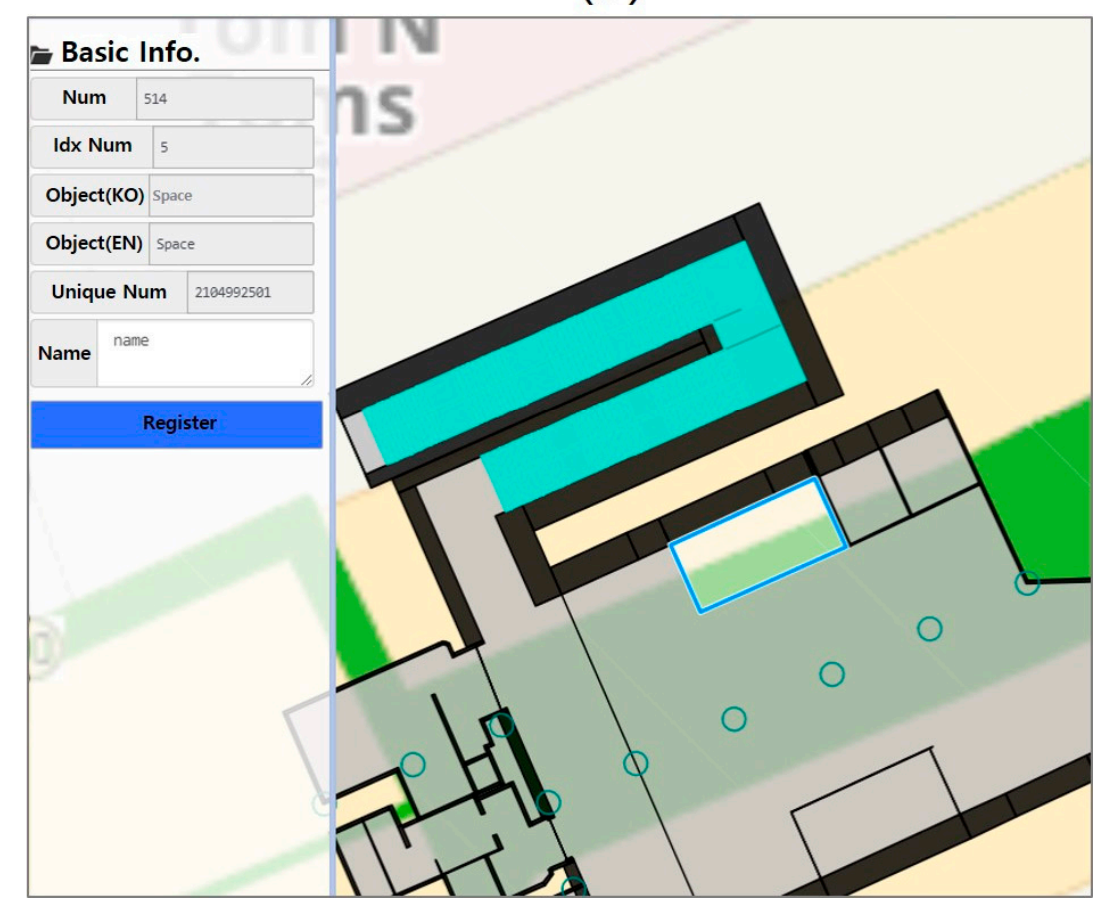

Figure 3. Implemented cases: (a) 2D data visualization, and (b) attribute information. 
(a)

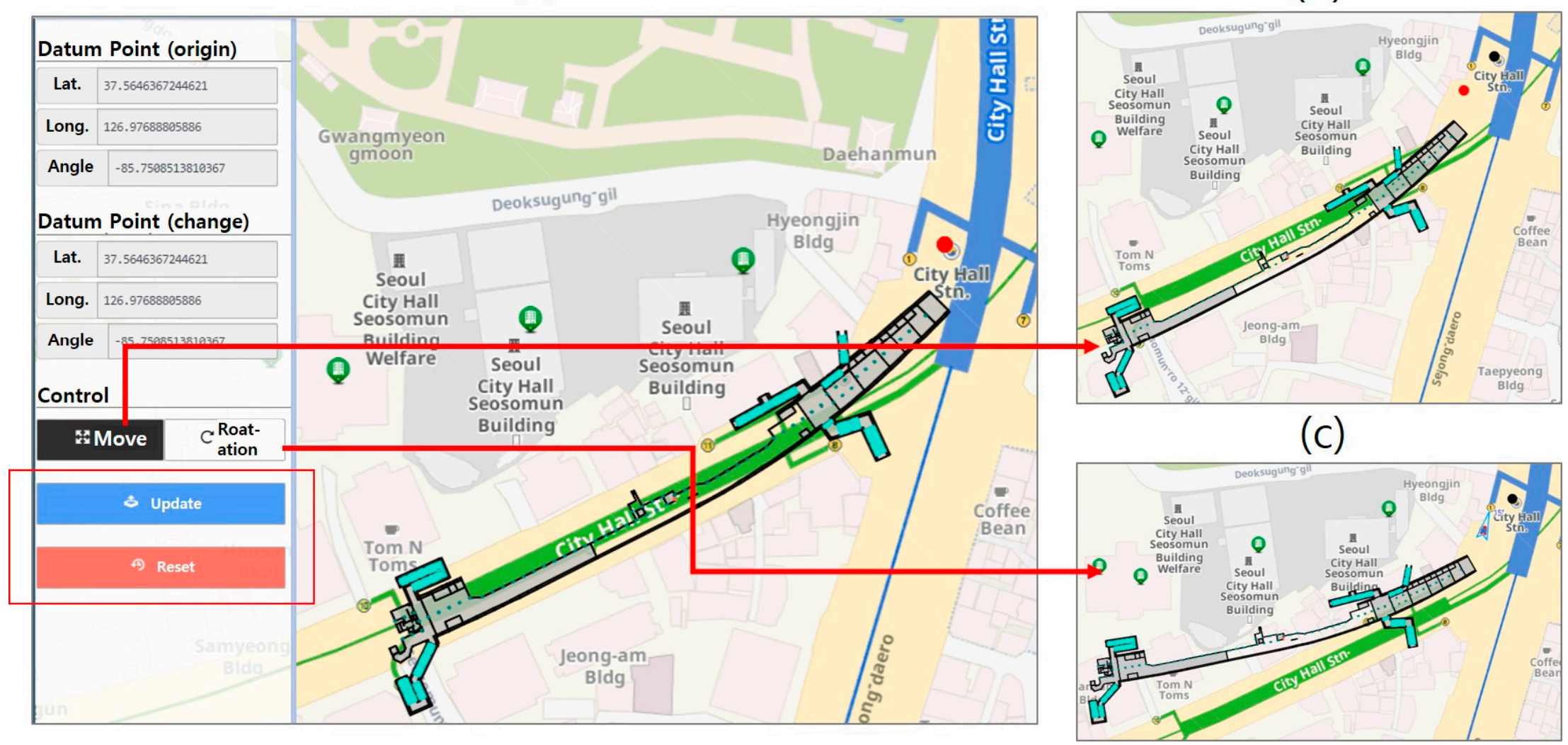

Figure 4. Two-dimensional data translation and rotation function: (a) user interface, (b) data translation, and (c) data rotation. 
Figure 4 shows the functionality required to modify the position data related to $2 \mathrm{D}$ information. The 3D model consists of the relative coordinates with a reference point for the absolute coordinates of the building. The reference points are used to obtain the absolute coordinates during the 2D conversion. Since the reference point may differ from the actual location, updating the actual 2D data is necessary when editing the reference point after cross-checking it on the actual online map. This modification involves moving or rotating the data on the map in relation to the reference point. Figure 4a depicts the user interface for data adjustment. Information about the reference points pre- and post-update are available, and radio buttons activate movement and rotation. When the update is complete, clicking the update button automatically uploads both the previously uploaded 2D data and the indoor POI absolute coordinate data to the latest coordinates. In addition to 2D data, the data update function displays two additional markers, indicated by red and black dots on the map. Red dots indicate displaced reference points, and black dots indicate original reference points. Figure $4 b, c$ shows the features that have been moved and rotated with a mouse drag and drop, respectively.

Figure 5 shows the functionality used to manage detailed information about the four groups of indoor POI classification schemes. Figure 5 a shows a detailed information management interface related to mobility and convenience facilities for the disabled. These facilities are available in seven indoor POI classification systems, which include elevators, escalators, lifts, moving walkways, flatwork, and toilet facilities. Attributes can be recorded for the corresponding POIs, and the pictures taken during installation can be uploaded. Figure $5 \mathrm{~b}$ shows a detailed information management interface for viewing shopping centers. A shopping center is composed of stores, which are detailed in the facility classification system. The shops can be further divided into different categories. The categories were divided into seven basic entities or large segments, such as medical, education, distribution, and sports facilities, and 51 detailed groups, such as restaurants, skin care centers, and bakeries. Administrative functions may include not only large sections and groups of stores, but also telephone numbers, trade names, and actual store photographs. Figure $5 \mathrm{c}$ displays a doorway that is a detailed item in a facility. In underground shopping malls and subway stations, the number of entrances must be available. As a result, detailed information about entrances and additional information about the mobility facilities that are included in the entrances should be entered. Figure $5 \mathrm{~d}$ shows the detailed information management function of the subway boarding locations. The subway boarding location is an indoor POI that is only included in a subway station. If the train consists of a maximum of 10 squares, and each block has four entrances, it is composed of numbers such as 1-1, 1-2, . , 2-1, 2-2. The subway gate details consist of the boarding numbers, the distance between the trains and the boarding numbers, and the comfort input near the gate. If data are entered through the functions in the menu system shown in Figure 4, the existing indoor POI can provide users with more detailed information about the internal facilities as well as location information inside the building. Of course, providing this information for users requires the creation of additional visualization services or the release of more data. 
(a)

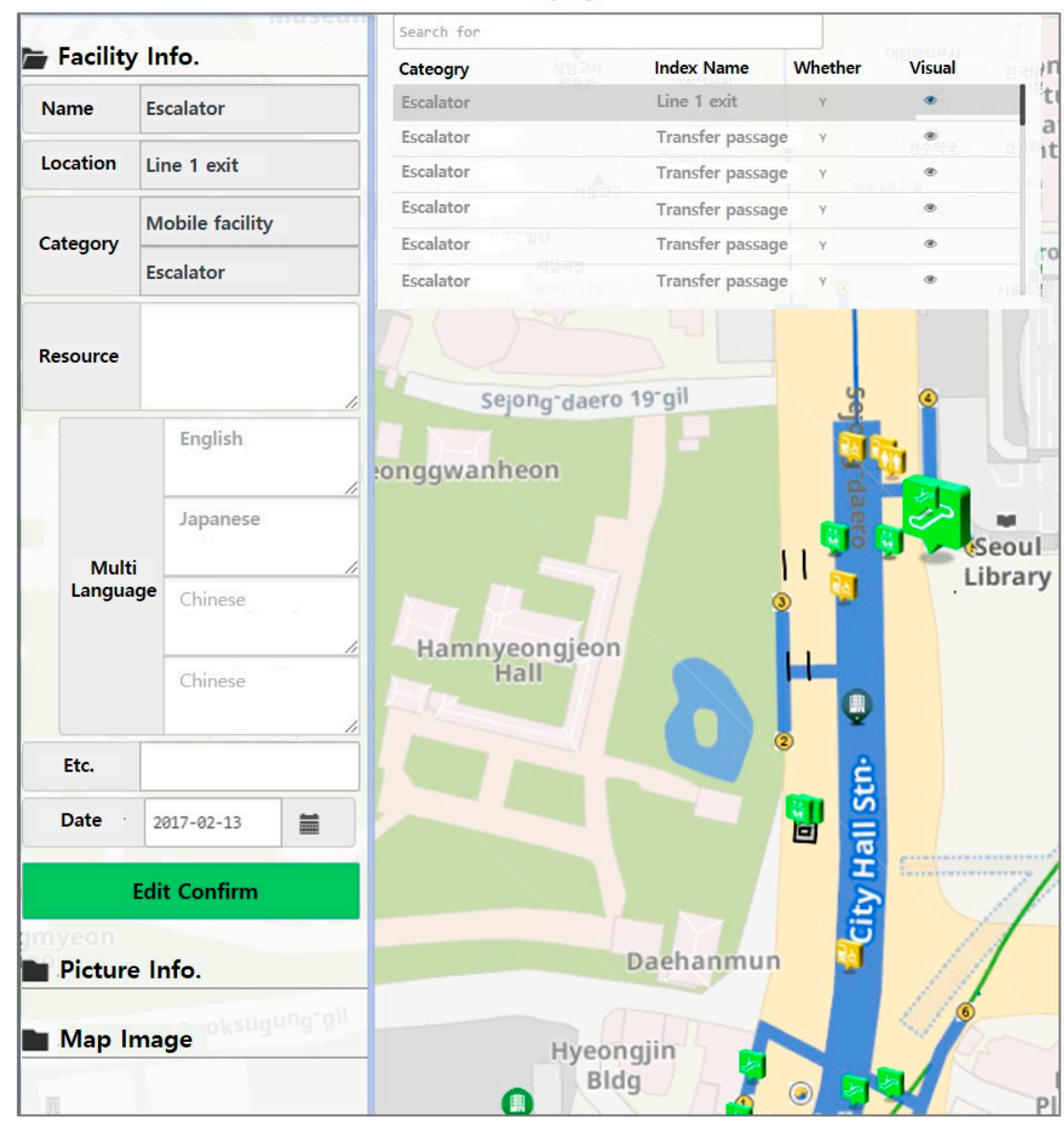

(b)

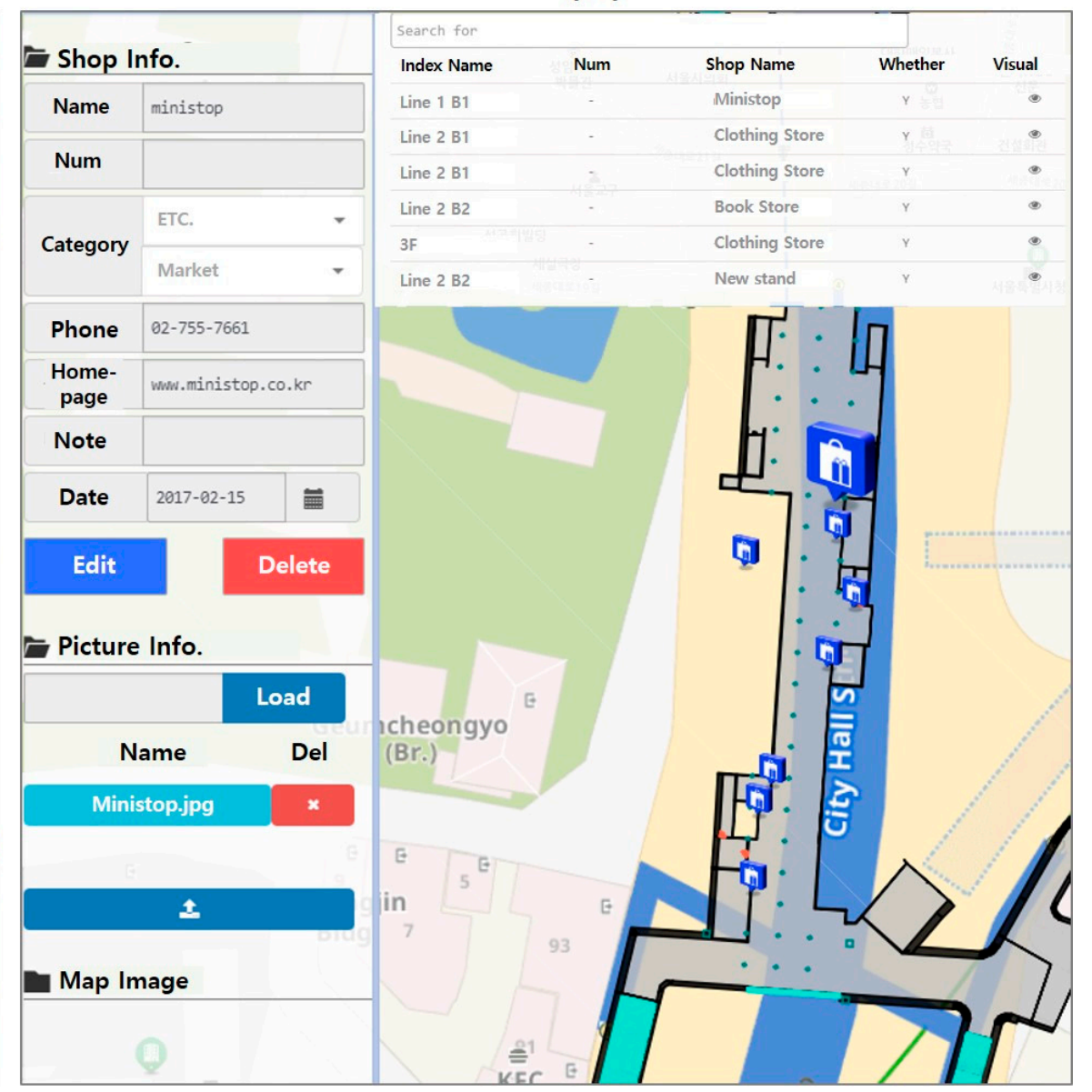

Figure 5. Cont. 
(c)

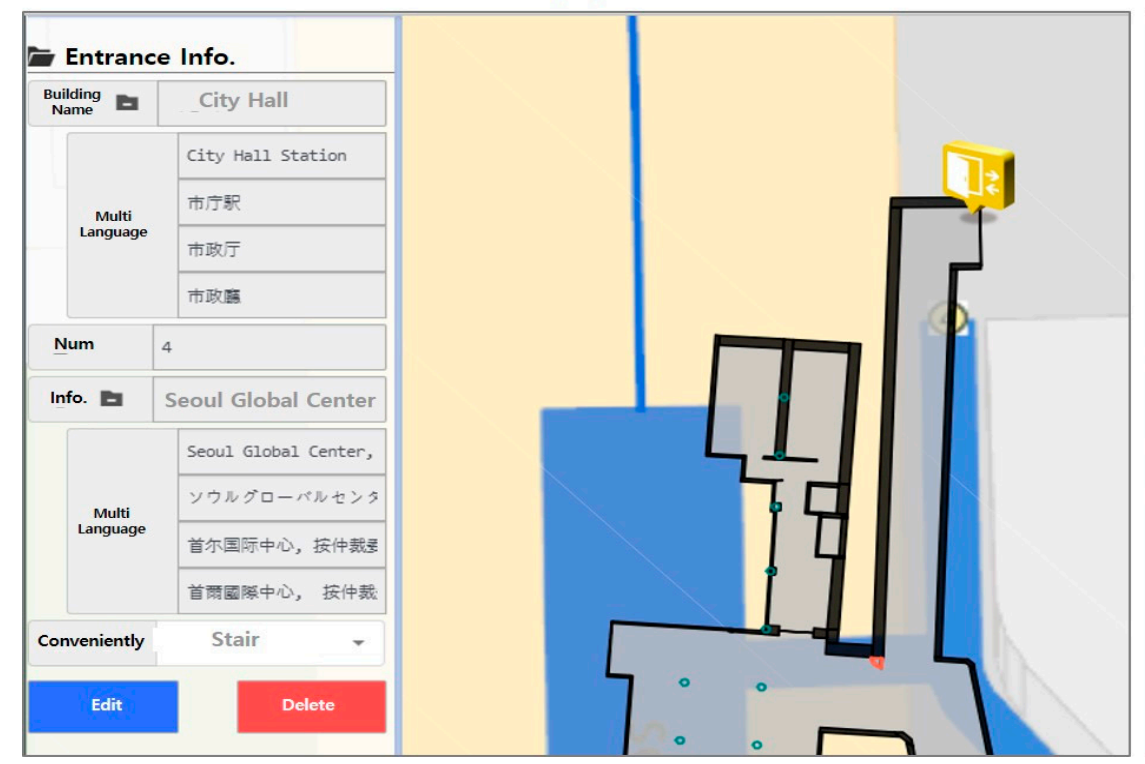

(d)

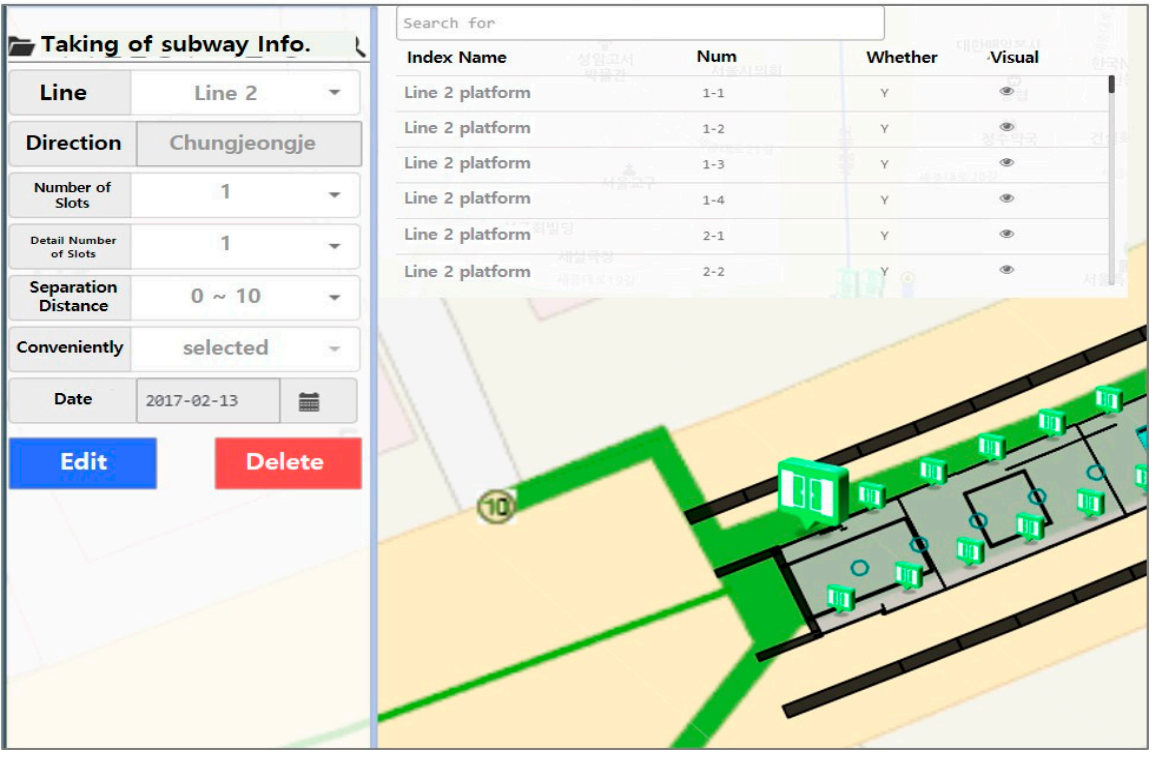

Figure 5. Management cases on indoor POI detail information: (a) facilities, (b) shopping center, (c) entrances, and (d) subway. 


\section{Open API of Indoor GIS}

The data service methods used by a public organization such as the Seoul City government holds the data that include the Open API and file format. The Open API delivery method can be somewhat difficult for general users to adopt, but it is an advantageous approach for developers and data visualization experts, as it is associated with the database system. Government agencies around the world produce some of the most intimate data related to our lives as public information. The indoor geospatial data shown in this study are also produced by local government authorities. In 2011, the United Nations issued open data program guidelines for the purpose of civic engagement and transparent use [19]. Since then, public data policies have been established in most countries, including the United States, the United Kingdom, and Japan [20,21]. In Korea, the law on the provision and use of public data was enacted and enforced in 2013 and is in line with these trends [22]. The classification system planned for activation and policy analysis was directed from various points of view [23,24].

The Open API designed and deployed in this study is summarized in Table 1. Not all data managed by the indoor geospatial information management system are provided in the Open API. The 2D indoor map consists of geometric information that includes the insides of buildings created with absolute coordinates. Objects such as walls, columns, windows, elevators, doors, spaces, stairs, and escalators inside buildings are generated with polygonal geometry to ensure the correct internal boundaries. The newly added data to the existing 2D data consist of detailed information on four kinds of POIs: handicap facilities, shopping centers, entrances, and subway usage. Additional available data are related to the surroundings, which include data about other public or underground buildings near the building. The indoor information system available to managers is under restricted access. However, if it is to be delivered as an Open API, the endpoint should be set on the same system to eliminate access limitations. Figure 6 shows the data processing flow after designing the endpoints for the data to be publicly available. Both the 2D data and the image data are kept in the file system, and the remainder is stored in the database table. If system users add the necessary parameters to the endpoint and submit it to the management system, the system searches for the data and presents it in JavaScript Object Notation (JSON). JSON is a text-exchange format based on the JavaScript language that is commonly used to provide web services. For 2D building data, the data are provided in the GeoJSON format, which has additional geographic information compared to JSON. GeoJSON is one of the standards used in GIS [25]. Detailed data are similarly structured for POI requests for internal facilities. Therefore, the endpoint is also designed to be requested according to a taxonomy that considers the convenience of use.

Figure 7 shows examples of the internal source codes to provide the Open API according to specifications for request and response processing that are shown in Figure 6. This implies that the endpoint configuration is built in the same way that it was designed and that the source code is processed to show the response results in JSON.

Table 1. List of open application programming interface (API)-related indoor geographic information systems (GISs) in the metropolitan government. GeoJSON, Geo-JavaScript Object Notation.

\begin{tabular}{|c|c|c|}
\hline Open API & Request & Detailed Information \\
\hline 2D Indoor Map & $\begin{array}{ll}\text { - } & \text { Building floor list } \\
\text { - } & \text { Layer data }\end{array}$ & $\begin{array}{ll}\text { - } \quad \text { Index names } \\
\text { GeoJSON objects (wall, column, } \\
\text { window, elevator, door, space, } \\
\text { stair, escalator) }\end{array}$ \\
\hline Handicap Facility & $\begin{array}{ll}- & \text { Facilities list } \\
- & \text { Detailed information } \\
- & \text { Pictures }\end{array}$ & $\begin{array}{ll}- & \text { Name } \\
- & \text { Location (index name) } \\
\text { - } & \text { Category (escalator, elevator, toilet, } \\
\text { disabled passenger boarding) } \\
\text { - } \quad \text { Resource }\end{array}$ \\
\hline
\end{tabular}


Table 1. Cont.

\begin{tabular}{|c|c|c|}
\hline Open API & Request & Detailed Information \\
\hline Shopping Center & $\begin{array}{ll}- & \text { Shopping center list } \\
- & \text { Information } \\
- & \text { Pictures }\end{array}$ & $\begin{array}{ll}- & \text { Name } \\
- & \text { Shop category } \\
- & \text { Phone number } \\
- & \text { Homepage } \\
- & \text { Note }\end{array}$ \\
\hline Entrance & $\begin{array}{ll}- & \text { Entrance list } \\
- & \text { Detailed information } \\
- & \text { Pictures }\end{array}$ & $\begin{array}{ll}- & \text { Building name } \\
- & \text { Entrance number } \\
- & \text { Entrance information } \\
- & \text { Mobile facilities }\end{array}$ \\
\hline $\begin{array}{l}\text { Subway } \\
\text { Usage }\end{array}$ & $\begin{array}{ll}\text { - } & \text { Taking list } \\
\text { - } & \text { Detailed information }\end{array}$ & $\begin{array}{ll}- & \text { Subway line } \\
- & \text { Direction } \\
- & \text { Vehicle number } \\
- & \text { Separation distance } \\
- & \text { Convenience distance }\end{array}$ \\
\hline Nearby & - $\quad$ Detailed information & $\begin{array}{ll}- & \text { Building name } \\
- & \text { Nearby information }\end{array}$ \\
\hline
\end{tabular}

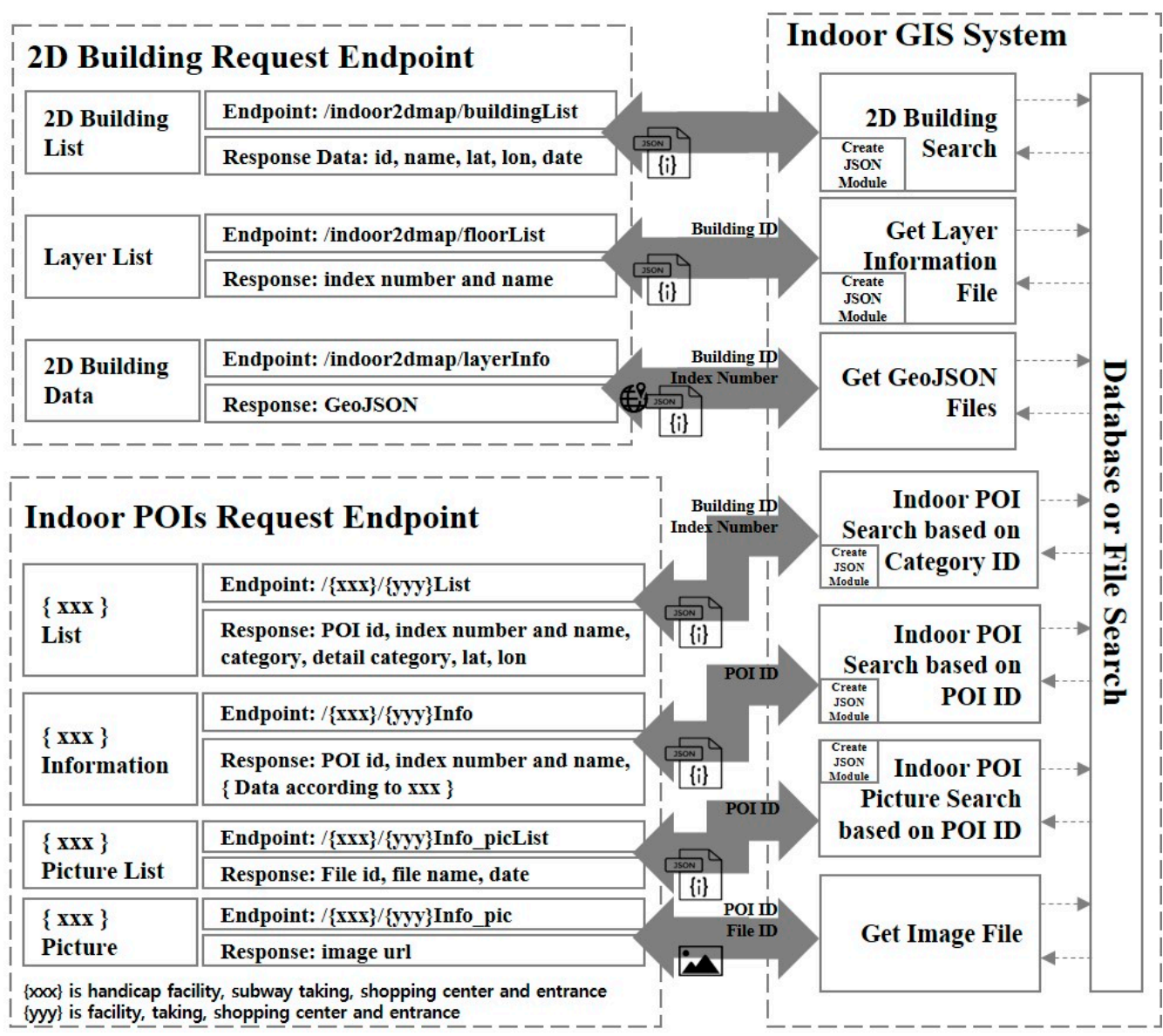

Figure 6. Conceptual view of request and response processing for an indoor POI and a 2D building. 

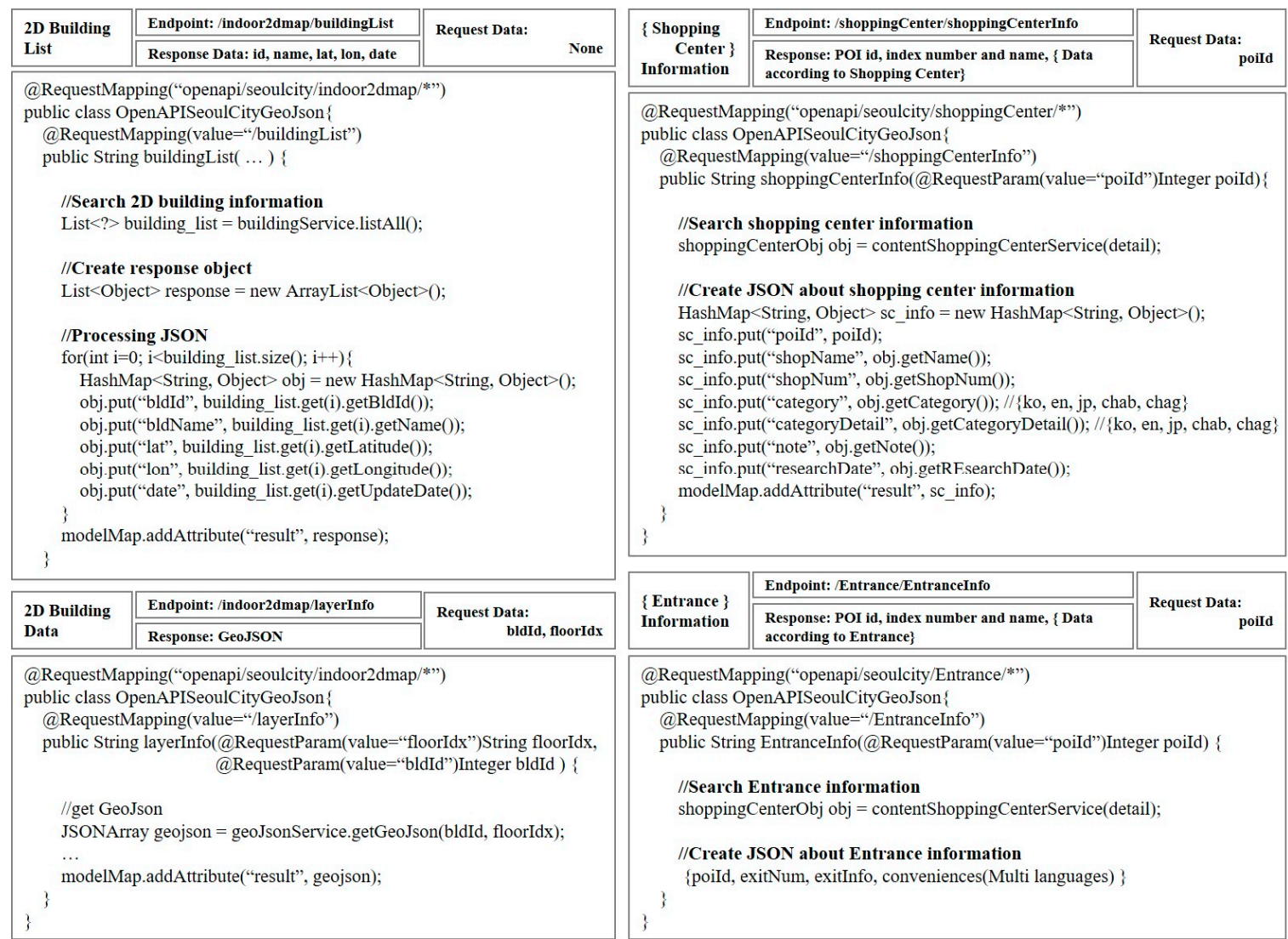

Figure 7. Implementation examples of an Open API related to 2D building information.

\section{Mobile Web Map Service of Indoor Contents}

Given the Open API method, anyone can access the indoor geospatial data service as long as they apply an association with a database to receive up-to-date information. For the design and deployment purposes of the implemented system, the possibilities of actual services for the data are planned to be published. Additionally, methods to improve public access to the Open API should be found. Because data provided with Open API are not subject to service dependencies, application services can originate in different phases. Many smart devices have been introduced with popular web browsers installed, and in this study, the reason for implementing mobile services was to endow field operators with account permission to immediately modify or edit services. In the process of building the 2D POI database, field operators can immediately apply the additional data models to conveniently enter attribute information.

The services provided through web browsers do not require separate installations and are easily accessible because they do not depend on a particular platform. The technology for building web services is also rapidly evolving, and the utility is improving. Therefore, the indoor geospatial information visualization service built in this study is an Internet application. The Open API for the indoor geospatial information provides detailed information about indoor POIs, as well as 2D data geometry information about buildings. Servers are configured when storing or processing data from separate data. In particular, the details are managed by simultaneously entering information not only in Korean, but also in English, Chinese, and Japanese. Using such services actively, indoor geospatial content visualization services for visitors from other countries have been introduced based on this study.

Figure 8 shows the main page for the visualization of indoor geospatial information for people from other countries. To satisfy the purpose of this study regarding the mobile environment, the test 
devices used were an iPad mini (Figure 8a) and an iPhone (Figure 8b) to test for visualization at different resolutions. The background map is in English. In Korea, the tile service is provided by deploying multilingual background maps across the metropolitan city to provide services for foreigners.

(a)

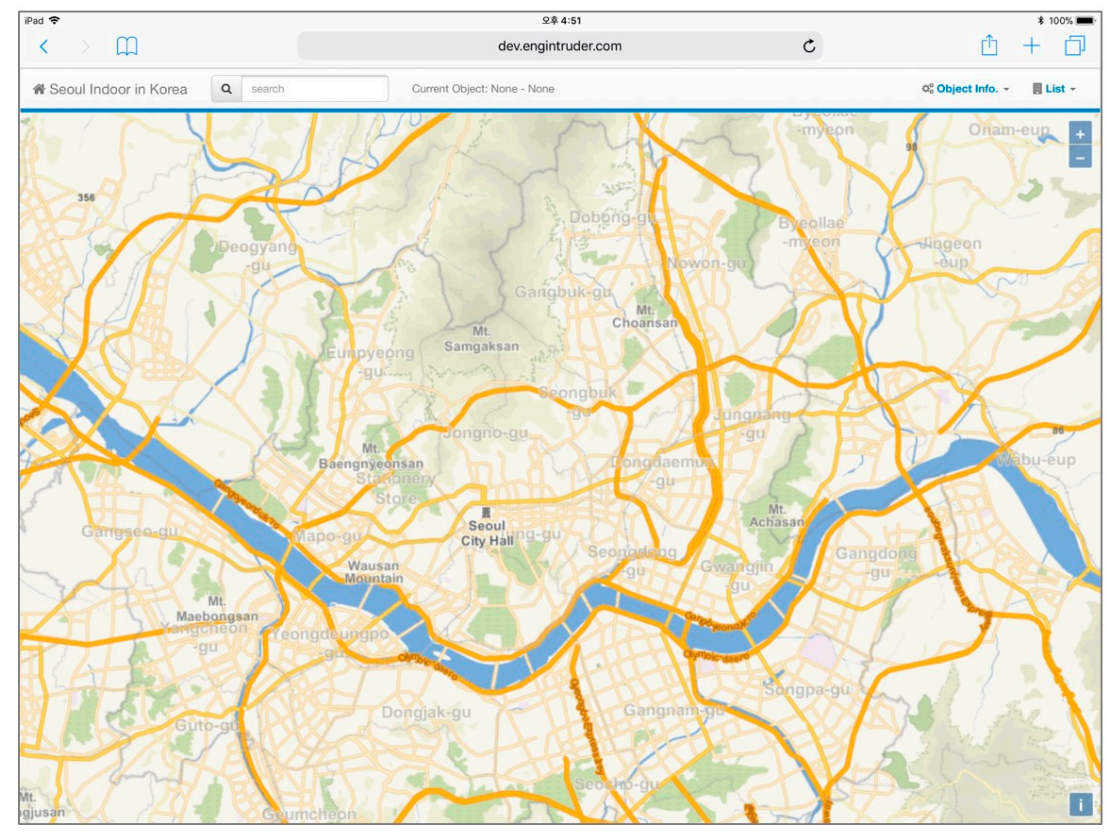

(b)

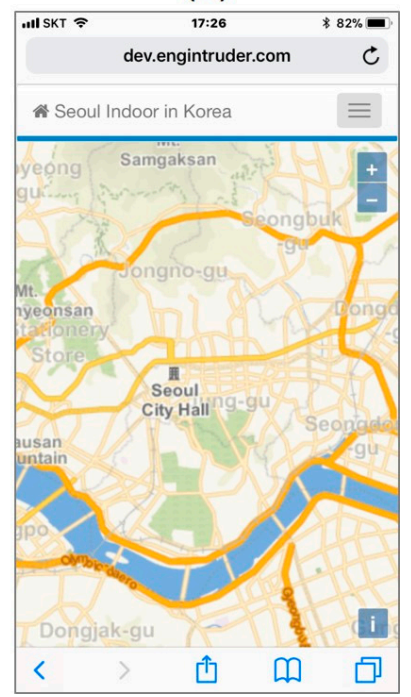

Figure 8. Main page of the mobile web mapping service for indoor facilities for foreigners using (a) iPad mini and (b) iPhone.

Figure 9 shows a small part of the source code and results in response to the Open API request for the indoor 3D object management system in the mobile mapping service. It shows the response received in JSON format by sending the required parameters to the URL that is set as an endpoint in the Open API.

Figure 10 shows a 2D building and a visualization of geometry data. As shown in Figure 6, this result is revealed in the "2D Building Endpoint" requests within the Open API. A list of 2D building objects can be obtained via the "2D Building List" request without any separate parameters. Figure 10a shows the buildings or basement facilities selected from the menu list. Then, the index information for the building is displayed in the index list of buildings in the object info menu; this index entry can be selected to display the index geometry information on the map. The types of geometric objects include walls, spaces, columns, doors, and stairs. The objects installed in each index are different. As the index geometry information changes, the object interface also changes the context. Visualization and detailed information about the 2D objects were visualized through requests for "Layer List" and "2D Building Data" with the object-specific numbers received from the "2D Building List" request as parameters. As geometry information is released, an interface is shown to visualize the locations of the internal POIs in the building. Figure 10b shows the iPhone results, and the four types of building-related information are presented: in-building space, mobility facility, access door, and shopping mall information.

Figures 11 and 12 show the results of visualizing indoor POI information and information in the vicinity of buildings. This result is also shown through the "Indoor POI Endpoint" request group in the Open API. As shown in Figure 11, the location of the facility is indicated by an icon that is activated on the map by turning on the building indoor POI visualization interface, which provides the building geometry information. POI geometry information includes latitude and longitude among the response to the "Indoor POIs" list request API (/\{xxx\}/\{yyy\}List). Selecting the corresponding POI icon displays the available details. Figure 11a-c show detailed information about the entrances, handicap facilities, 
and shopping center, respectively. The detailed items are visualized through the endpoint suffix "Info" request, and the associated information can also be viewed for additional information, such as pictures. Figure 12 shows information about the neighborhood of a building in a separate panel. Figure 12a represents the format displayed on an iPad mini, and Figure $12 \mathrm{~b}$ shows the format displayed on an iPhone. The name of the current building is displayed and information about other nearby buildings is shown.
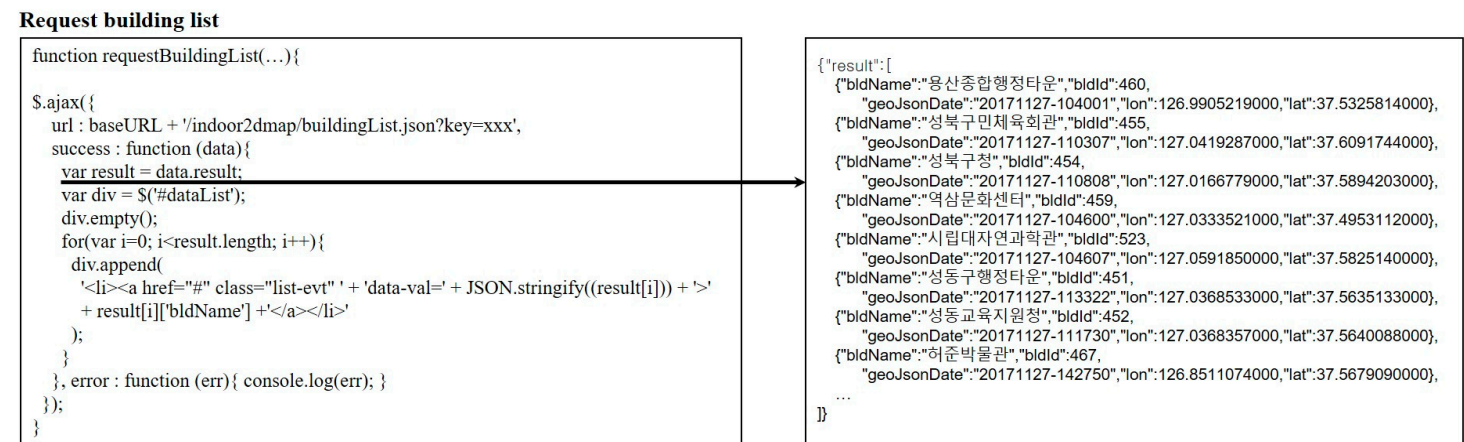

Request GeoJSON

\begin{tabular}{|c|c|}
\hline $\begin{array}{l}\text { function requestBuildingData(bldId, floorIdx, callback) } \\
\text { var url = baseURL + '/indoor2dmap/layerInfo.json?key=xxx' } \\
\quad+\text { '\&bldId ='+ bldId + '\&floorIdx =' + floorIdx; } \\
\text { \$.ajax (\{ } \\
\text { url : url, } \\
\text { success : function (evt) }\{ \\
\text { try }\{ \\
\quad \text { var result = JSON.parse(evt.result): }\end{array}$ & 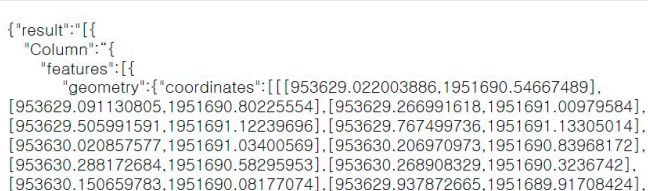 \\
\hline $\begin{array}{l}\text { if }(\text { callback != null)\{ } \\
\quad \text { callback }(\text { result }) ; \\
\} \text { catch }(\mathrm{e})\{\text { console.log(evt.result); \} }\end{array}$ & 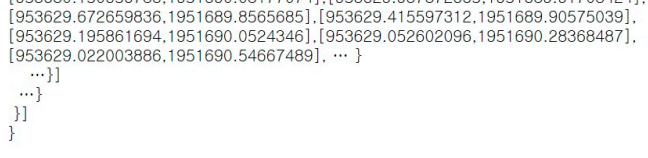 \\
\hline
\end{tabular}

Figure 9. Application examples of requests by JavaScript and their responses based on Open API and GeoJSON.

(a)
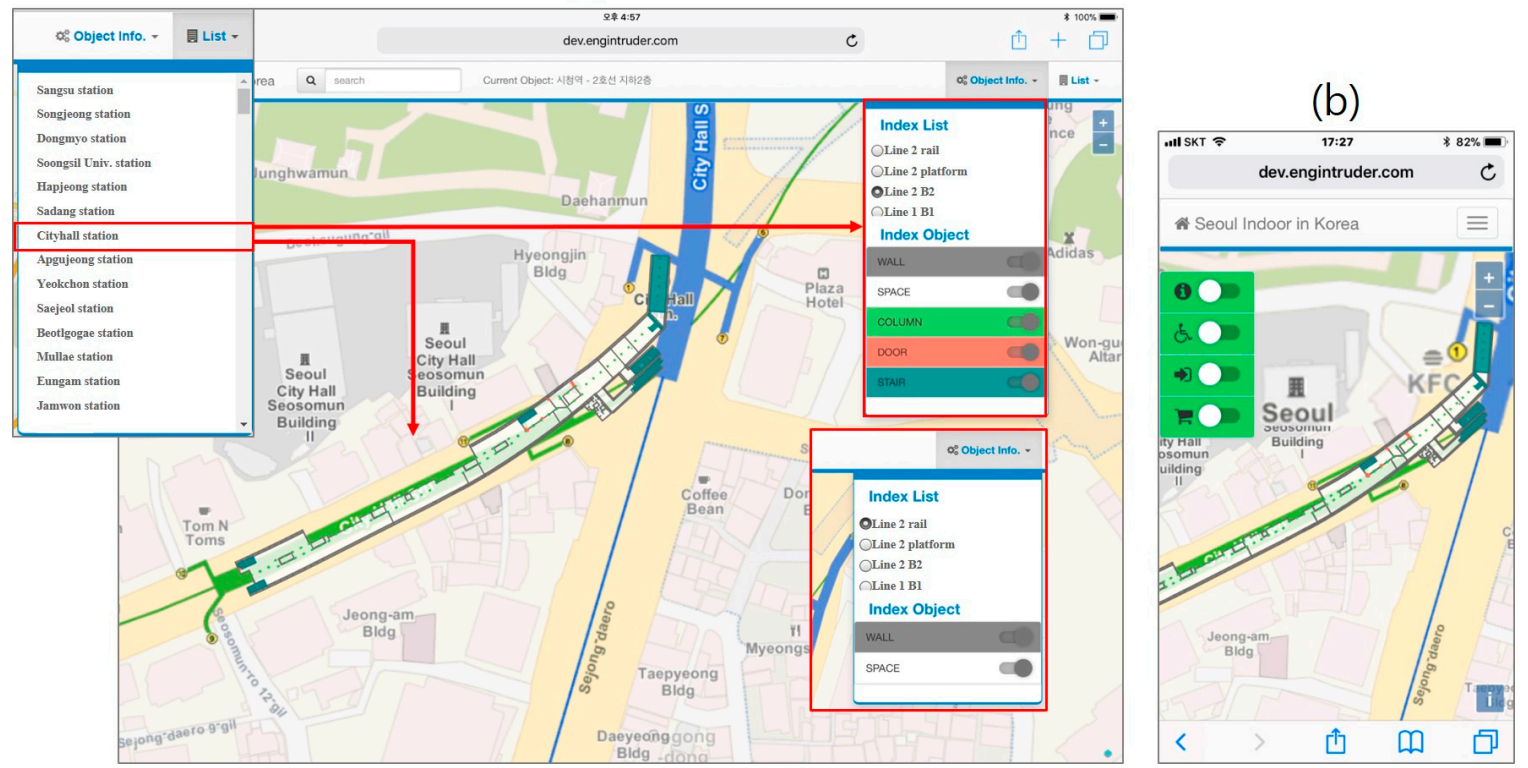

Figure 10. Results of the 2D building visualization, object selection, and indoor POI radio button for (a) iPad mini and (b) iPhone. 
(a)

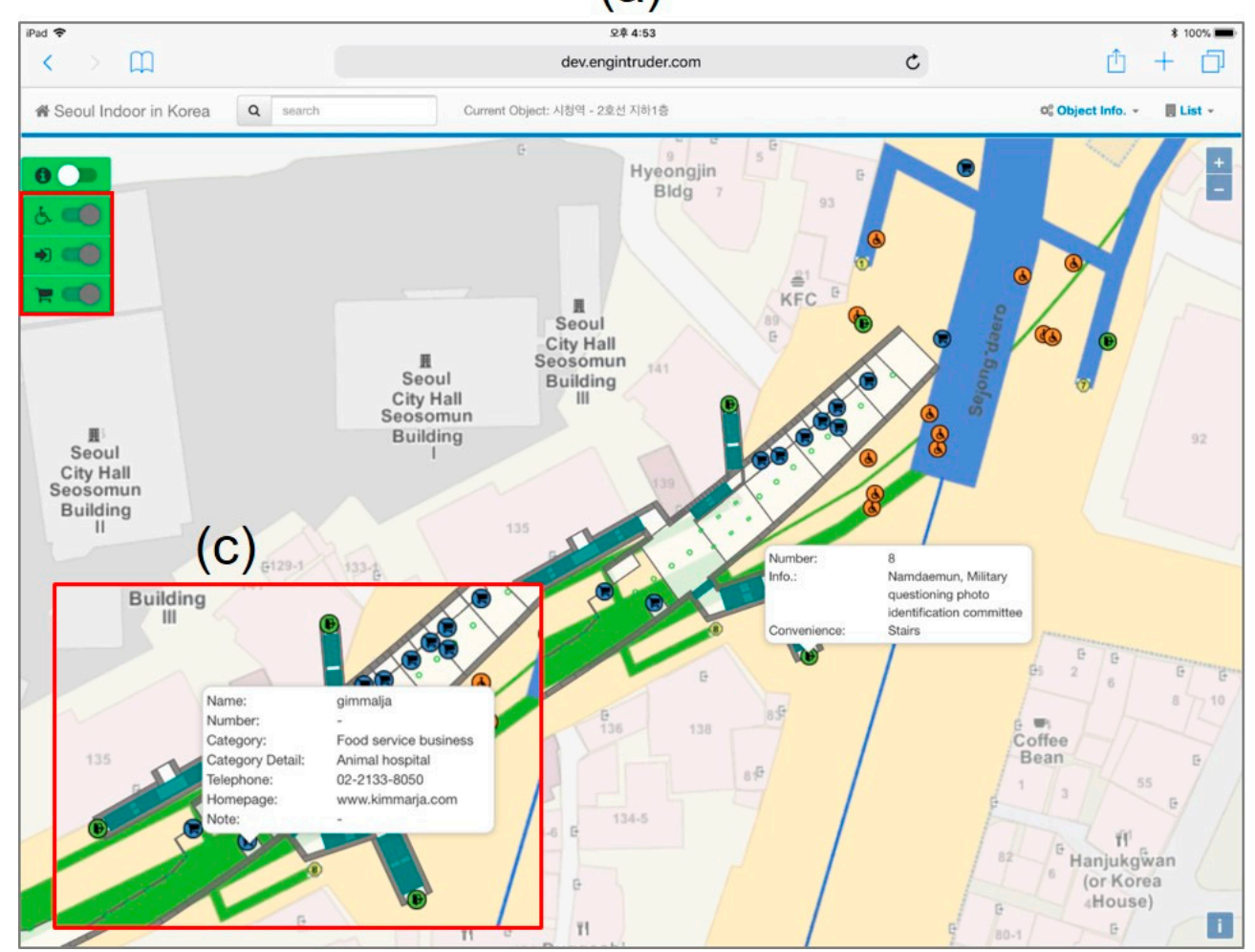

(b)

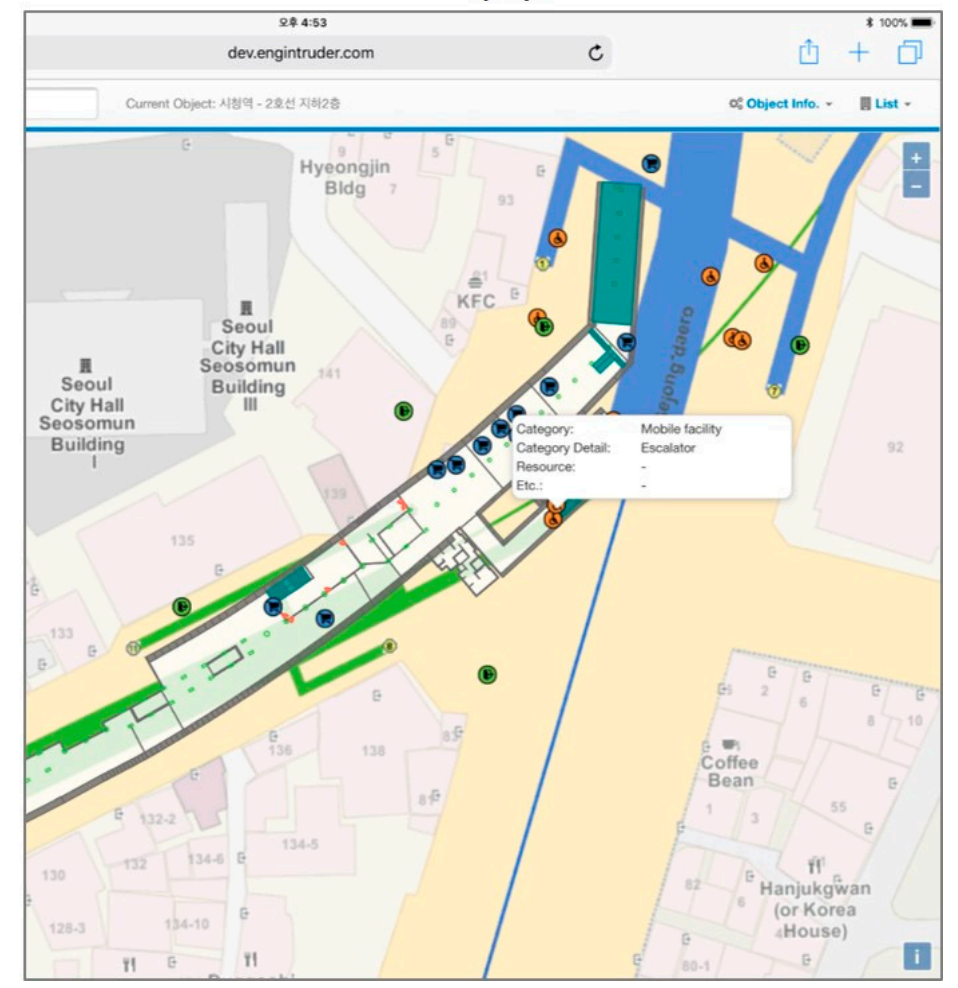

Figure 11. Visualization results of indoor POI detailed information: (a) entrance, (b) handicap facility, and (c) shopping center. 
(a)

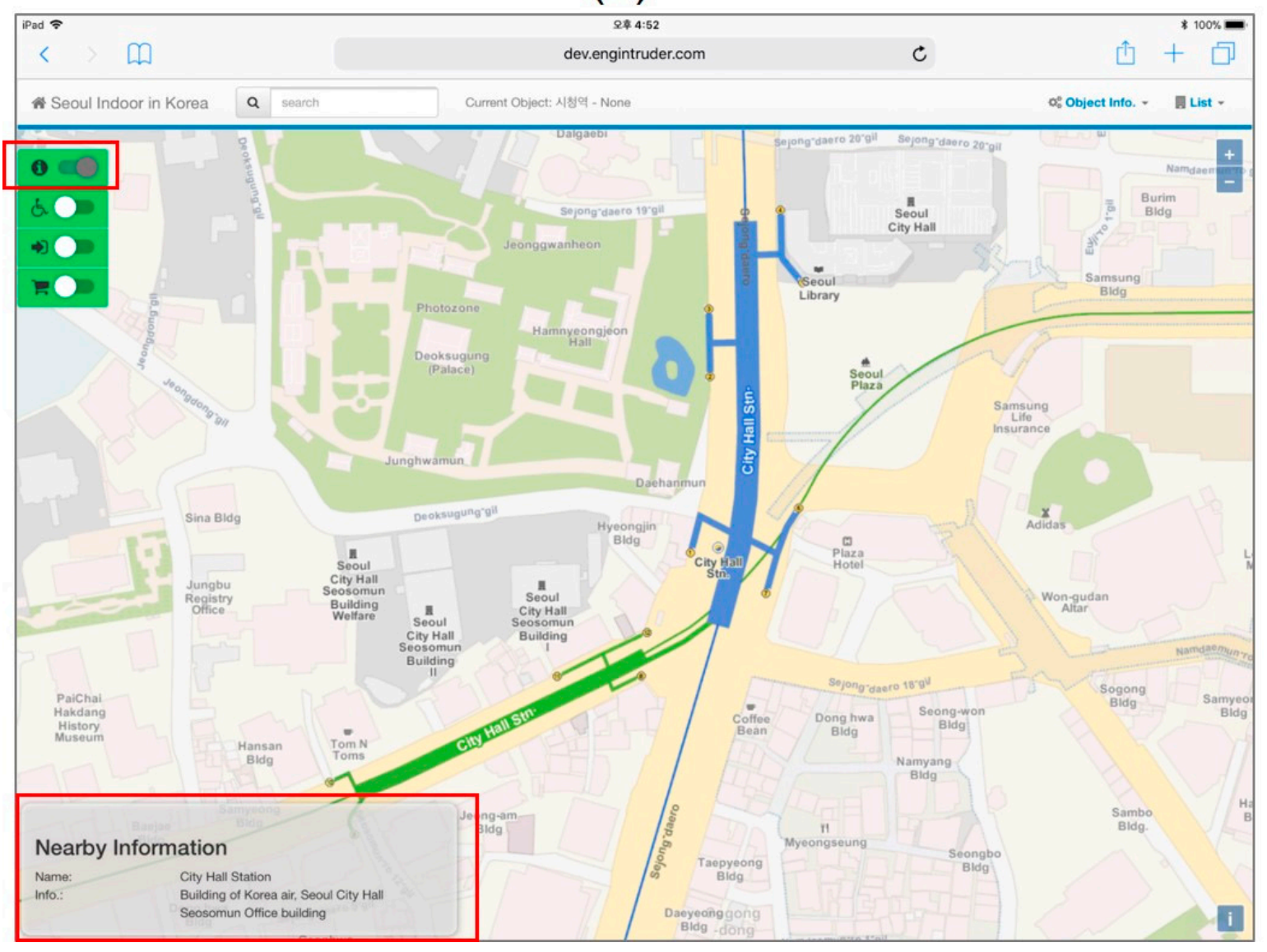

(b)

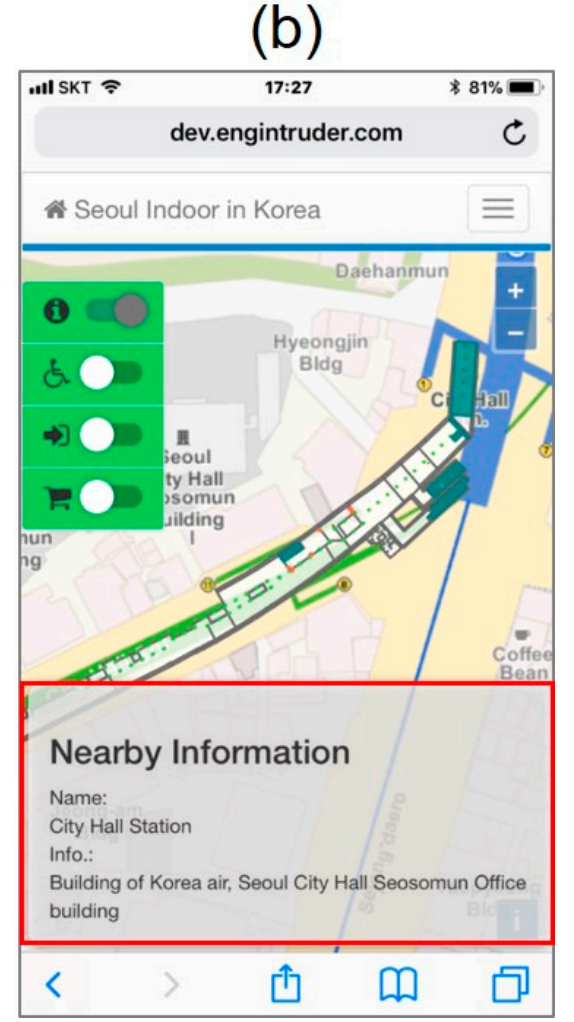

Figure 12. Visualization results of detailed information about a nearby building on (a) iPad mini and (b) iPhone. 


\section{Discussion}

The main result of this study is a suggested method for using indoor 3D objects to input and edit POI on the surface. In this approach, the 2D POI database generation process includes 3D building object information such as walls, windows, and stairs used for 3D modeling, and building reference point information that consists of absolute coordinates. The indoor POI information is stored in the database as relative coordinates. To convert $2 \mathrm{D}$ building objects from relative coordinates to absolute coordinates, the reference point with absolute coordinates of building objects that include latitude, longitude, and rotation angle are used, and then converted into GeoJSON format. By adding GeoJSON data to the administrator system, the indoor POI relative coordinates stored in the database are automatically converted to absolute coordinates by utilizing the same reference points with absolute coordinates.

In particular, since field operators most commonly use POI on mobile devices, all these tasks were implemented in the mobile environment. This is a case study using actual Seoul data, providing a practical method for handling POI deployment in 3D interior information databases and 2D web services. However, this scheme can be applied independent of regional characteristics. In this study, the implemented indoor geospatial information management system is an expanded system for managing detailed information on internal facility POIs based on 2D data. Extended 2D geometry information and POI locations were automatically created by converting the existing modeled 3D data, rather than creating a new model. For POI locations, the database link with 3D model information allows continual updates.

The implemented systems show some advantages in terms of use. Deploying indoor 3D models as an additional service requires direct data requests and separate technology to provide visualization. However, 2D models can be used at the same time as requests, because they are provided through Open API, which was designed to be easier to visualize than 3D models. From a processing perspective, 2D models can be converted automatically using existing 3D models, so that they are not produced separately. Additional data links with user-oriented properties are also possible. In addition, direct links with outdoor services are possible through the coordinate system used in 2D web mapping on the mobile environment. Absolute coordinates for a central point in a 3D model can be used, so that the use of indoor POI details managed by the added 2D management system can be expanded, since they are also visualized in the 3D model.

As a result of deploying application systems using Open API, we have some suggestions for further work. Using a service in real-life conditions should not be too complex. Nevertheless, checking and using the Open API user guide is somewhat complicated, resulting in overlapping requests. Such requests need to be validated and configured to be more usable through an elaborate design from the users' perspective. If an application system is to be developed in the future, it will be a good source of information for traveling foreigners. However, some multilingual entries are still insufficient. For instance, only Korean is available to obtain data on the index and lists of buildings. Management of the information is ineffective, so it is necessary to add or release additional information. In addition, a clear definition of building index information is required. An index list that represents floors inside a building can be viewed, but identifying the desired floor by merely checking index names is often difficult. The indoor geospatial information management system maintains some additional information besides the data available with Open APIs. Geometric information includes property information management, index detail management, and outside area management for space objects. This information is expected to be used to develop more diverse services to be provided by Open APIs, after confirming whether or not it is open.

Map services, which are widely used, furnish information about indoor entities. Even so, these maps only offer brief geometric information. Information about an internal facility shows the position of an item but does not provide details. In this regard, the information on indoor spaces in a metropolitan city, as reviewed in this study, is highly useful for providing information about indoor facilities. Notably, anyone can use the map service because it is provided with Open APIs. The 
addition of movement information, geometric attribute information, and index information for major indoor facilities that are controlled in the system is expected in the future to develop more services.

\section{Conclusions}

Many types of indoor geospatial interfaces have been created for indoor building-related POIs. Data compiled in the database of a metropolitan city were used to build 2D geometries and topological relationships. Thus, 2D geometries should be built according to the exact geo-coordinate system for that country or region using optimized surveying techniques. Based on the indoor 3D geospatial information management system in the metropolitan city, we carried out a case study with add-on functions to manipulate and manage information by adding 2D building data linked to 3D models and by reorganizing the classification system of the POIs of each internal facility. To enhance public usability, a portion of the information used in this scheme can be offered below the Open API. Information on amenities may be used to build services for handicapped people. The detailed 2D data were exchanged with GeoJSON format. First, this was helpful in visualizing exact 2D building locations by requesting indoor geometry information. As such, POI locations in a building can be requested and checked, which has the potential to provide visualization services by requesting detailed database attributes, including 3D model attributes for route guidance when requesting desired POI details. POI locations can immediately connect with external maps that are available from other organizations.

The significance of this study can be summarized as follows. The first added functionality is a method to relate indoor 3D contents to POIs for 2D objects on the ground level. The 2D geometric data used in this study were not directly converted from 3D graphical data, but from 2D model data that were made of relative coordinates separate from geo-referenced coordinates, for indoor 3D graphical data modeling. Therefore, conversion processes for 3D to 2D data were not required in this work, but this requires additional coordinate system matching on the surface. If an indoor 3D database such as the one in Seoul already exists, there is no need for additional work on creating or modifying 2D features of the surface. The second added functionality is the POI configuration. Unlike POIs on the surface, POIs for indoor geo-based contents need additional attributes. For this purpose, a taxonomy was presented in this study. The third is that it operates in a mobile environment, so that system users can directly enter and manage the attributes that are often obtained in the field. All of the experiments in this study were performed on mobile devices such as tablets and smartphones. Finally, it was shown that it is easy to implement these services through the Open APIs. It technically supports open policies that are implemented by almost all public institutions.

Author Contributions: K.L. conceptualized the research objectives, drafted the manuscript, and provided revisions. K.K., under K.L.'s supervision, performed system implementation.

Acknowledgments: This research was supported by the National Land Space Information Research Program from the Ministry of Land, Infrastructure and Transport, Korea (No. 14NSIP-B080144-01).

Conflicts of Interest: The authors declare no conflict of interest.

\section{References}

1. Serrao, M.; Rodrigues, J.M.F.; Rodrigues, J.I.; du Buf, J.M.H. Indoor localization and navigation for blind persons using visual landmarks and a GIS. Procedia Comput. Sci. 2012, 14, 65-73. [CrossRef]

2. Pereira, C.; Sousa, A.; Filipe, V. Open-Source indoor navigation system adapted to users with moto disabilities. Procedia Comput. Sci. 2015, 67, 38-47. [CrossRef]

3. Basiri, A.; Lohan, E.S.; Moore, T.; Winstanley, A.; Peltola, P.; Hill, C.; Amirian, P.; e Silva, P.F. Indoor location based services challenges, requirements and usability of current solutions. Comput. Sci. Rev. 2017, 24, 1-12. [CrossRef]

4. Tashakkori, H.; Rajabifard, A.; Kalantari, M. A new 3D indoor/outdoor spatial model for indoor emergency response facilitation. Build. Environ. 2015, 89, 170-182. [CrossRef]

5. OpenStreetMap. Available online: https://www.openstreetmap.org/ (accessed on 7 March 2018). 
6. Lei Gong, L.; Kanamori, R.; Yamamoto, T. Data selection in machine learning for identifying trip purposes and travel modes from longitudinal GPS data collection lasting for seasons. Travel Behav. Soc. 2018, 11, 131-140. [CrossRef]

7. Wua, C.; Yee, X.; Fu Ren, F.; Du, Q. Check-in behaviour and spatio-temporal vibrancy: An exploratory analysis in Shenzhen, China. Cities 2018, 77, 104-116. [CrossRef]

8. Willing, C.; Klemmer, K.; Brandt, T.; Neumann, D. Moving in time and space-Location intelligence for carsharing decision support. Decis. Support Syst. 2018, 99, 75-85. [CrossRef]

9. Touya, G.; Antoniou, V.; Olteanu-Raimond, A.-M.; Van Damme, M.-D. Assessing crowdsourced POI quality: Combining methods based on reference data, history, and spatial relations. ISPRS Int. J. Geo-Inf. 2017, 6, 80. [CrossRef]

10. David Jonietz, D.; Zipf, A. Defining fitness-for-use for crowdsourced points of interest (POI). ISPRS Int. J. Geo-Inf. 2016, 5, 149. [CrossRef]

11. Liu, X.; Wang, X.; Wright, G.; Cheng, J.C.P.; Li, X.; Liu, R. A state-of-the-art review on the integration of building information modeling (BIM) and geographic information system (GIS). ISPRS Int. J. Geo-Inf. 2017, 6, 53. [CrossRef]

12. Oldfield, J.; Van Oosterom, P.; Beetz, J.; Krijnen, T.F. Working with open BIM standards to source legal spaces for a 3D Cadastre. ISPRS Int. J. Geo-Inf. 2017, 6, 351. [CrossRef]

13. Santos, F.; Almeida, A.; Martins, C.; Gonçalves, R.; Martins, J. Using POI functionality and accessibility levels for delivering personalized tourism recommendations. Comput. Environ. Urban 2017. [CrossRef]

14. Ahn, S.; Sim, M.; Go, J.; Kim, K.; Choi, Y. Service plans for indoor spatial information. Transp. Res. Procedia 2017, 21, 180-188. [CrossRef]

15. Fernandez-Carames, C.; Serrano, F.J.; Moreno, V.; Curto, B.; Rodriguez-Aragon, J.F.; Alves, R. A real-time indoor localization approach integrated with a geographic information system. Robot. Auton. Syst. 2016, 75, 475-489. [CrossRef]

16. Seoul Indoor Map Service. Available online (only Korean version): http://indoormap.seoul.go.kr/ (accessed on 14 May 2018).

17. Kim, S.; Kim, J.; Jung, J.; Heo, J. Development of a 3D underground cadastral system with indoor mapping for as-built BIM: The case study of gangnam subway station in Korea. Sensors 2015, 15, 30870-30893. [CrossRef] [PubMed]

18. Seoul 3D GIS. Available online: http://3dgis.seoul.go.kr/ (accessed on 7 March 2018).

19. Dawes, S.S.; Vidiasova, L.; Parkhimovich, O. Planning and designing open government data programs: An ecosystem approach. Gov. Inf. Q. 2016, 33, 15-27. [CrossRef]

20. Song, H.; Hwang, S. Seeking strategies for local governments to prepare for public data act. J. Korean Assoc. Reg. Inf. Soc. 2014, 17, 1-28.

21. Wang, H.J.; Lo, J. Adoption of open government data among government agencies. Gov. Inf. Q. 2016, 33, 80-88. [CrossRef]

22. Kim, J.; Lee, D.H.; Bae, S.H. A study on the current legal issues of the re-use of the public-sector data in Korea. Korean Lawyers Assoc. 2014, 63, 5-45.

23. Kim, D.G.; Joo, W.K.; Kim, E.; Lee, Y.H. A case study on classification system design for public sector information typology. J. Digit. Converg. 2014, 12, 51-68. [CrossRef]

24. Hong, Y.W. A study on the invigorating strategies for open government data. J. Korean Data Inf. Sci. Soc. 2014, 25, 769-777. [CrossRef]

25. GeoJson. Available online: https:/ /geojson.org/ (accessed on 7 March 2018).

(C) 2018 by the authors. Licensee MDPI, Basel, Switzerland. This article is an open access article distributed under the terms and conditions of the Creative Commons Attribution (CC BY) license (http://creativecommons.org/licenses/by/4.0/). 